\title{
Perceptual Learning in Flavor Aversion: Evidence for Learned Changes in Stimulus Effectiveness
}

\author{
C. A. J. Blair and Geoffrey Hall \\ University of York
}

\begin{abstract}
Rats were exposed to the compound flavors $\mathrm{AX}$ and $\mathrm{BX}$, presented in alternation, and to $\mathrm{CX}$ on a separate block of trials. Generalization to BX after aversion conditioning with AX was less than to CX. An equivalent effect was found when the nature of the common element was changed after preexposure but not when the common element was omitted during preexposure, during conditioning and test, or both. Rats conditioned with $\mathrm{X}$ alone again showed less aversion to BX than to CX; similarly, rats conditioned with a novel flavor (Y) showed less aversion to BY than to CY. These effects support the proposal that intermixed preexposure to $\mathrm{AX}$ and $\mathrm{BX}$ enhances the perceptual effectiveness of their unique features, $\mathrm{A}$ and $\mathrm{B}$.
\end{abstract}

Our standard theories of classical conditioning concern themselves principally with the conditions under which associations are formed between the central representations of external events. They say little about how such representations are activated. They assume the existence of a representational node for each of the stimuli that can be demonstrated to be effective as a conditioned stimulus (CS) or unconditioned stimulus (US) and then simply assume that presentation of the stimulus will evoke activity in its corresponding node, the level of activity being determined by the intensity of the stimulus. For many purposes these assumptions seem to cause no problems. An issue arises, however, when we allow the possibility that the ability of a given stimulus to activate its node, or even the nature of the node that is activated, may change with experience. The various phenomena that have been taken as instances of perceptual learning (see Hall, 1991) attest to the reality of this possibility. Evidently a comprehensive and satisfactory theory of associative learning will not be possible without a specification of the learning processes that determine the relationship between the external stimulus and the nature and strength of the activation its occurrence induces in its central representation. The experiments reported in this article investigated this matter in the context provided by studies of the effects of exposure to compound flavors on the subsequent ability of rats to discriminate between them.

In their demonstration of the perceptual learning effect in flavoraversion learning in rats, Symonds and Hall (1995) gave subjects in the critical experimental condition (Group I, for intermixed) alternating preexposure trials with two similar stimuli, AX and BX (where A and B represent distinctive features of the two stimuli, and $\mathrm{X}$ represents an explicitly added common element). Control subjects (Group B, for blocked) received a block of AX trials followed by a block of BX trials or vice versa. It was found that an

This work was supported by a studentship from the Biotechnology and Biological Science Research Council to C. A. J. Blair. We thank C. Bonardi, E. Mondragón, and P. Quinlan for helpful discussion.

Correspondence concerning this article should be addressed to C. A. J. Blair or Geoffrey Hall, Department of Psychology, University of York, York YO10 5DD, United Kingdom. E-mail: cajb100@york.ac.uk or gh1@york.ac.uk aversion conditioned to one of the stimuli (AX) generalized less well to the other (BX) in Group I than in Group B, a result that has been amply confirmed in subsequent experiments (e.g., Bennett \& Mackintosh, 1999; Mondragón \& Hall, 2002). This effect has been taken to indicate that the opportunity to compare similar stimuli (as was available to Group I) increases the ease with which they can subsequently be discriminated. Mondragón and Hall (2002) postulated the existence of a special perceptual learning process that operated during the preexposure phase for Group I, acting to enhance the perceptual effectiveness or salience of the unique elements, A and B, and to reduce that of the common element, X. Because the salience of a CS may be assumed to determine the rate at which conditioning occurs to it, these changes in salience mean that associative strength should accrue principally to A rather than to $\mathrm{X}$ during conditioning with $\mathrm{AX}$. Generalization to $\mathrm{BX}$ (which will depend largely on the strength governed by X) would thus be limited in Group I. In addition, it is possible that the presence of a salient, or perceptually dominant, B element in the test compound might interfere with perception of the $\mathrm{X}$ element, reducing the ability of any association governed by this element to determine performance.

The account offered by Mondragón and Hall (2002) accepts the notion that the ability of a given event to activate its central representation could be modified by experience and implies the existence of a special learning process responsible for such modifications. McLaren, Kaye, and Mackintosh (1989; see also McLaren \& Mackintosh, 2000), however, have pointed out that standard associative learning principles, when suitably applied, may be capable of providing an explanation for the differing effects of intermixed and blocked preexposure. One possibility derives from consideration of the implications of the fact that the preexposure to the stimuli will allow the formation of associations between the various elements of the compound stimuli. In both training schedules, excitatory within-compound associations (between $\mathrm{A}$ and $\mathrm{X}$ and between $\mathrm{B}$ and $\mathrm{X}$ ) can be expected to form. Additionally, the intermixed procedure could allow the development of inhibitory associations between the unique features (A and B) of the preexposed stimuli, A being present on those trials when $\mathrm{B}$ is absent and vice versa (for direct evidence supporting this proposition, see Dwyer, Bennett, \& Mackintosh, 2001). When, 
after conditioning with $\mathrm{AX}$, animals in Group B are tested with $\mathrm{BX}$, their response will be partly determined by the ability of $\mathrm{X}$ (by way of the $\mathrm{X}-\mathrm{A}$ association) to contact a representation of the US. This source of responding will not be available to animals in Group I for whom the presence of B on test will serve to inhibit activation of the representation of A.

Another somewhat simpler possibility (again proposed by McLaren et al., 1989) can be derived from consideration of the role of latent inhibition. Generalization from AX to BX may be presumed to depend largely on the associative strength governed by features they hold in common (i.e., the X stimulus and any other intrinsic common elements shared by two flavored solutions). Latent inhibition induced by preexposure to the stimuli will reduce the amount learned about the common elements and thus tend to restrict generalization. Now the experimental design used by Symonds and Hall (1995) ensured that both groups received the same total amount of exposure to the stimuli, which might be thought enough to ensure that latent inhibition was equated in the two groups. But, given that our understanding of the mechanisms responsible for latent inhibition is still incomplete, it remains possible that latent inhibition to the $\mathrm{X}$ element when presented in compound with the A and B elements might be influenced by the schedule of preexposure and might develop more readily after intermixed preexposure to $\mathrm{AX}$ and $\mathrm{BX}$ than after blocked preexposure. If so, then the former group would be expected to show less generalization than the latter. Direct testing of the associative strength governed by the $\mathrm{X}$ element alone gives some support to this possibility; although Bennett and Mackintosh (1999) failed to detect any difference between the two preexposure conditions, Mondragón and Hall (2002), using preexposure procedures directly comparable with those used by Symonds and Hall (1995), found that X evoked a weaker aversion in Group I than in Group B.

The experiments to be described here continued the analysis of this version of the perceptual learning effect (i.e., of the difference between the effects of intermixed and blocked preexposure on generalization in flavor-aversion learning) with the intention of providing evidence that will allow choice between the rival accounts. These experiments did so by making use of a novel, within-subjects experimental design in which each individual experienced both the intermixed and blocked schedules during preexposure. Experiment 1 focused on establishing the reality and reliability of the perceptual learning effect in this procedure. The effect obtained in this experiment, it will be argued, cannot be explained in terms of an account based on the degree to which common stimulus elements suffer latent inhibition. Subsequent experiments exploited the procedure in an attempt to determine the source of the effects obtained, specifically, to contrast the predictions made by the associative account of McLaren and Mackintosh (2000), with those of the alternative interpretation offered by Mondragón and Hall (2002).

\section{Experiments 1a, 1b, and 1c}

In the first of these experiments (for a summary of the designs, see Table 1), all subjects (rats) received exposure trials with three compound flavor stimuli, AX, BX, and CX, followed by aversion conditioning with $\mathrm{AX}$ as the CS. Generalization to $\mathrm{BX}$ and to $\mathrm{CX}$ was then tested for all subjects. Presentations of AX and BX were given according to an intermixed schedule - there were two trials each day, with $\mathrm{AX}$ being presented in the morning and $\mathrm{BX}$ in the
Table 1

Experimental Designs

\begin{tabular}{lcc}
\hline \multicolumn{1}{c}{$\begin{array}{c}\text { Experiment number and } \\
\text { preexposure condition }\end{array}$} & Conditioning & Test \\
\hline 1a: AX/BX \& CX & $\mathrm{AX}+$ & $\mathrm{BX} \& \mathrm{CX}$ \\
1b: BX/AX \& CX & $\mathrm{AX}+$ & $\mathrm{BX} \& \mathrm{CX}$ \\
1c & $\mathrm{AX}+$ & $\mathrm{BX} \& \mathrm{CX}$ \\
$\quad$ Paired group: AX/BX \& CX & $\mathrm{AX} /+$ & $\mathrm{BX} \& \mathrm{CX}$ \\
Unpaired group: AX/BX \& CX & $\mathrm{AX}+$ & $\mathrm{BX} \& \mathrm{CX}$ \\
2 & $\mathrm{~A}+$ & $\mathrm{B} \& \mathrm{C}$ \\
X group: AX/BX \& CX & & \\
No-X group: A/B \& C & $\mathrm{A}+$ & $\mathrm{B} \& \mathrm{C}$ \\
3 & $\mathrm{AX}+$ & $\mathrm{BX} \& \mathrm{CX}$ \\
X-P group: AX/BX \& CX & $\mathrm{AY}+$ & $\mathrm{BY} \& \mathrm{CY}$ \\
X-CT group: A/B \& C & $\mathrm{AX}+$ & $\mathrm{BY} \& \mathrm{CY}$ \\
4a: AX/BX \& CX & $\mathrm{X}+$ & $\mathrm{BX} \& \mathrm{CX}$ \\
4b: AX/BX \& CX & $\mathrm{Y}+$ & $\mathrm{BY} \& \mathrm{CY}$ \\
5a: AX/BX \& CX & & \\
5b: AX/BX \& CX & &
\end{tabular}

Note. A, B, C, X, and $\mathrm{Y}$ represent different flavors; + indicates an injection of LiCI. AX/+ for Experiment 1c indicates that the injection was not paired with the flavor.

afternoon; presentations of CX occurred as a separate block of trials, both of the daily exposures using this stimulus. If this procedure generates a perceptual learning effect paralleling that obtained with the between-subjects design of Symonds and Hall (1995), then it might be expected that the generalized aversion to BX would be less profound than that to CX.

Experiment 1b was identical to Experiment 1a, except that the order of presentation of the stimuli during the intermixed phase of preexposure was reversed, with AX (the stimulus subsequently used as the CS) being presented in the afternoon, and BX being presented in the morning.

Experiment 1c was conducted to confirm that the effects obtained in Experiments $1 \mathrm{a}$ and $1 \mathrm{~b}$ were a consequence of the conditioning procedure used in those experiments. One group of rats received training identical to that used in Experiment 1a; a second group was treated in the same way, except that they received unpaired presentations of $\mathrm{AX}$ and the US rather than AX-US pairings prior to the test. Effects that depend on generalization from the CS to the test stimuli in the first of these groups should be absent in the second.

\section{Method}

Subjects and apparatus. The subjects in Experiment 1a were 8 experimentally naive male hooded Lister rats, with a mean ad lib weight of $403 \mathrm{~g}$ at the start of the experiment. An additional 8 rats from the same stock (mean ad lib weight: $330 \mathrm{~g}$ ) were used in Experiment 1b, and an additional 16 rats (mean ad lib weight: $394 \mathrm{~g}$ ) were use in Experiment 1c. The rats were singly housed with continuous access to food in a colony room that was artificially lit from 8:00 a.m. to 8:00 p.m. each day. Access to water was restricted, as detailed following.

The solutions used as experimental stimuli were administered in the home cages at room temperature in 50-ml plastic centrifuge tubes, each equipped with a rubber stopper to which was fitted a stainless steel, ball-bearing tipped spout. The following flavored compound solutions were used: a compound consisting of .00003 M quinine sulphate and .16 M saline $(\mathrm{NaCl})$, a compound consisting of $.00003 \mathrm{M}$ quinine sulphate and $.165 \mathrm{M}$ sucrose, and a compound consisting of .00003 M quinine sulphate and $2 \%$ lemon ( $2 \%$ lemon by volume; "ReaLemon" natural strength lemon 
juice supplied by ReaLemon, Ramsdonk, Belgium). Consumption was measured by weighing the tubes before and after trials, to the nearest $.1 \mathrm{~g}$. The US for the conditioning trials was an intraperitoneal injection of . $3 \mathrm{M}$ lithium chloride $(\mathrm{LiCl})$ at $10 \mathrm{ml} / \mathrm{kg}$ of body weight.

Procedure. For Experiment 1a, a schedule of water deprivation was initiated by removing the standard water bottles overnight. On each of the following 3 days access to water was restricted to two daily sessions of 30 $\mathrm{min}$, at 11:00 a.m. and 5:00 p.m. Presentation of fluids continued to be given at these times daily throughout the experiment.

Over the next 6 days (the preexposure phase), all subjects received four presentations of each of the three flavors: AX, BX, and CX. Half of the animals were first given 4 days intermixed access to Flavors AX and BX, with $10 \mathrm{ml}$ of $\mathrm{AX}$ presented during the first daily drinking session and 10 $\mathrm{ml}$ of $\mathrm{BX}$ presented during the second. (Although the drinking tubes contained $10 \mathrm{ml}$, the structure of the tube meant that a small amount of fluid remained inaccessible to the animal, with the result that the maximum amount consumed on a given trial was approximately $9 \mathrm{ml}$.) The next 2 days consisted of blocked presentations of CX in which $10 \mathrm{ml}$ of this flavor was made available in both morning and afternoon drinking sessions. The remainder of the subjects received the blocked presentations of $\mathrm{CX}$ on the first 2 days of the phase followed by 4 days of AX and BX. For all animals, Flavor A was lemon and Flavor X was quinine. The critical test flavors, B and $\mathrm{C}$, were counterbalanced, with half of the animals receiving sucrose as $\mathrm{B}$ and saline as $\mathrm{C}$, and half receiving the reverse arrangement.

Three conditioning trials followed. The first was given in the morning session the day after preexposure ended. It consisted of a 30-min presentation of $10 \mathrm{ml}$ of AX followed immediately by an injection of $\mathrm{LiCl}$. The rats were given free access to water in the afternoon session. The next day was a recovery day on which animals were given unrestricted access to water on both morning and afternoon drinking sessions. The second conditioning trial, given in the morning session of the next day, was identical to the first and was followed by an additional recovery day. The third conditioning trial was identical to the second. Water was again available in the afternoon session following this conditioning trial, and one additional recovery day preceded the test phase of the experiment.

On the following morning session, subjects were given a free-access test for $30 \mathrm{~min}$, with half receiving Flavor BX and half receiving Flavor CX. Water was made available for $0.5 \mathrm{hr}$ in the afternoon session. The next morning animals that had been tested with $\mathrm{BX}$ the previous day were given a test with $\mathrm{CX}$ and vice versa.

The procedure for Experiment $1 \mathrm{~b}$ was identical to that just described except that the schedule of flavor presentation during the intermixed phase was changed so that all $\mathrm{BX}$ presentations occurred during the morning sessions and, correspondingly, all AX presentations occurred during the afternoon sessions. In addition, because consumption of AX was substantially suppressed by the third conditioning trial in Experiment 1a, only two reinforced $\mathrm{AX}$ trials were given in this experiment (and in subsequent experiments).

For 8 of the 16 rats in Experiment 1c (paired group) the procedure was the same as that described for Experiment 1a, except that, as in Experiment $1 \mathrm{~b}$, only two conditioning trials were given. The other 8 (unpaired group) differed only in the treatment given during the conditioning phase. On sessions on which the paired group was given $\mathrm{AX}$, the unpaired group was given access to water for $30 \mathrm{~min}$. Both groups were then given the injection of $\mathrm{LiCl}$. Free access to water was given to both groups in the afternoon sessions. On the recovery days, when the paired group received access to water on both sessions, the unpaired group received $10 \mathrm{ml}$ of Flavor AX in the morning session and water in the afternoon session. Exposure to AX and to the US was thus matched in the two groups.

\section{Results and Discussion}

Experiment 1a. There was some evidence of neophobia on the first trial of the preexposure phase in that the group mean consumption score was $4.64 \mathrm{ml}$ (range: $3.60-7.68 \mathrm{ml}$ ). Thereafter, the rats consumed almost all of the fluid made available; the group mean over all the subsequent 11 trials of this stage was $8.59 \mathrm{ml}$, and on no trial was it less than $8.00 \mathrm{ml}$. (This pattern of consumption was seen during the preexposure phase of all subsequent experiments, and the data from this phase will not be considered further.) The conditioning procedure successfully established an aversion to AX, with all rats consuming the full volume of available fluid on the first conditioning trial but drinking a mean of 3.55 $\mathrm{ml}$ on Trial 2 and a mean of $0.20 \mathrm{ml}$ on Trial 3. All animals showed a reduced level of consumption from one trial to the next.

The results of the test phase, group means for consumption of $\mathrm{BX}$ and $\mathrm{CX}$, are presented in the top left panel of Figure 1. It shows that the rats consumed less of CX than of BX. A withinsubjects, one-way analysis of variance (ANOVA) confirmed that difference between the two test stimuli was statistically reliable, $F(1,7)=31.30$ (here and elsewhere a significance level of $p<.05$ was adopted). This outcome is consistent with the suggestion that generalization from the CS (AX) occurred less readily to a stimulus $(\mathrm{BX})$, presentations of which were intermixed with those of AX during preexposure, than to a stimulus $(\mathrm{CX})$ that was presented in a separate block of trials during preexposure.

A possible interpretation of the results obtained in this experiment is that time of day may serve as a cue that can mediate generalization. The aversion to AX was established by means of conditioning trials in which $\mathrm{AX}$ was presented during the morning
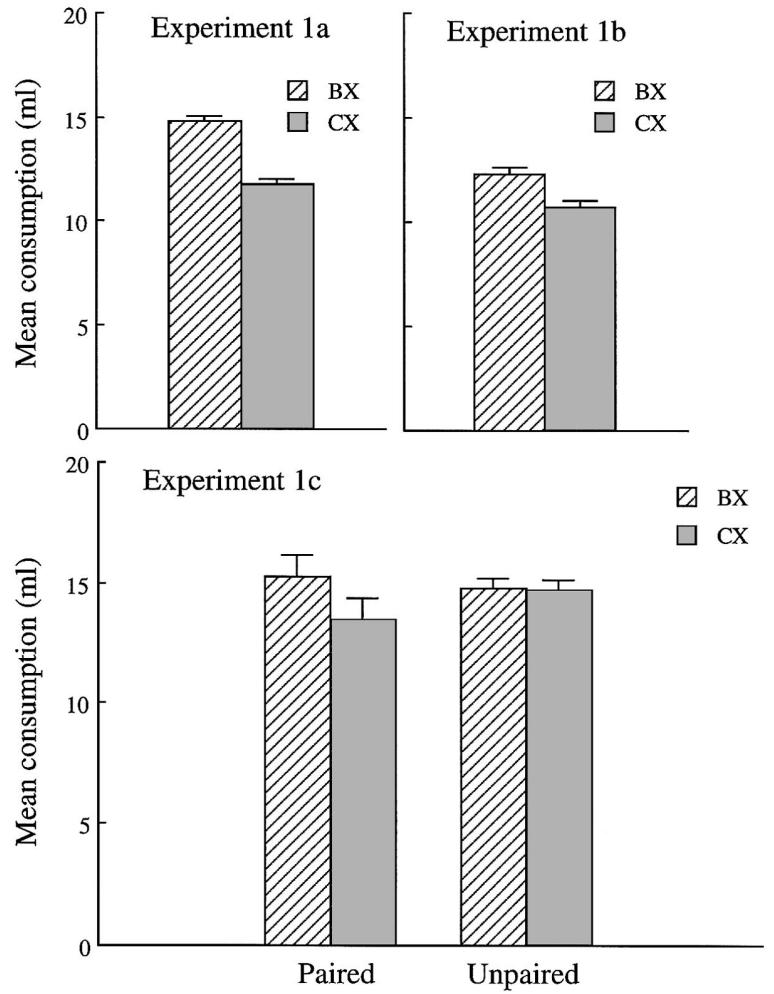

Figure 1. Experiment 1: Group mean consumption of the compound flavors BX and CX after aversion conditioning with AX (Experiments 1a and $1 \mathrm{~b}$ and the paired group of Experiment 1c; the unpaired group received separate presentations of AX and the unconditioned stimulus). All animals received initial preexposure to a block of $\mathrm{CX}$ trials and to trials with $\mathrm{AX}$ and BX presented in alternation. Error bars represent within-subjects standard errors, computed on scores adjusted for variation between subjects (Bakeman \& McArthur, 1996). 
drinking session. CX was presented in the morning on two occasions during the preexposure phase, whereas $\mathrm{BX}$ was presented exclusively in the afternoon sessions. If time of day can serve as an effective cue and if the flavor presented at a given time can become associated with this cue, then the association with $\mathrm{CX}$ might be expected to be stronger than that with $\mathrm{BX}$. If CX is better able than BX to activate the (conditioned) time-of-day cue, then the aversion governed by $\mathrm{CX}$ on test might be stronger than that governed by BX. Experiment $1 \mathrm{~b}$ provided a test of this interpretation.

Experiment $1 b$. In this experiment the critical test stimulus, $\mathrm{BX}$, was presented on morning sessions during preexposure. The CS (AX) was again trained in a morning session. In this case, generalization effects based on time of day predict that the pattern of result obtained in Experiment 1a should be reversed, with generalization to CX (a cue presented, on occasions, in the afternoon) being less than to $\mathrm{BX}$ (a cue presented solely in the mornings).

As in Experiment 1a, the conditioning procedure successfully established an aversion to AX (on the second of the conditioning trials the mean consumption of AX was $3.33 \mathrm{ml}$, with all animals showing a decline from Trial 1). The top right panel of Figure 1 shows group means for consumption on the test. The pattern of results was the same as in Experiment 1a, with subjects consuming more of $\mathrm{BX}$ than of $\mathrm{CX}, F(1,7)=6.14$. We conclude that the difference between $\mathrm{BX}$ and $\mathrm{CX}$ on test depends critically on the schedule used during preexposure (i.e., on BX being alternated with $\mathrm{AX}$ ) rather than on effects determined by the particular time of day at which presentations occurred during preexposure. Seeking further support for this conclusion we conducted an overall analysis of the test results of Experiments $1 \mathrm{a}$ and $1 \mathrm{~b}$, the variables being group (i.e., AX presented in the morning vs. AX presented in the afternoon) and test flavor (BX vs. CX). This yielded a significant effect only of the latter variable, $F(1,14)=30.27$; the effect of group, $F(1,14)=2.84$, and the interaction, $F(1$, $14)=2.94$, were not significant. Although the results of this cross-experiment comparison must be treated with caution, they contain nothing to indicate that the nature or size of the effect of interest might depend critically on the time of day at which presentations of AX occurred.

Experiment 1c. We have assumed so far that the effect seen on the test in Experiments 1a and 1b depended on differences in the degree to which the aversion conditioned to AX generalized to $\mathrm{BX}$ and CX. It is possible, however, that the preexposure schedule used in these experiments brings about differences in the rates at which neophobia habituates to the three stimuli and that this, rather than generalization, could be responsible for the outcome. As only $10 \mathrm{ml}$ of fluid was presented on each preexposure trial, differences in habituation might not be visible until the test when larger volumes of BX and CX were available; in addition, experience of the US might serve to sensitize the animal and enhance the degree of neophobia subsequently observed. According to this interpretation, the difference between BX and CX on test should be evident in the unpaired group as well as in the paired group in the present experiment.

The conditioning phase successfully established an aversion to AX in the paired group; group mean consumption on Trial 1 was $9.40 \mathrm{ml}$ and on Trial 2 was $4.12 \mathrm{ml}$. No aversion was evident in the unpaired group; on Trial 1 the group mean score was 8.58 $\mathrm{ml}$, and on Trial 2 it was $8.52 \mathrm{ml}$. An ANOVA, with group and trial as the variables, showed there to be a significant effect of group, $F(1,14)=11.88$, and trial, $F(1,14)=36.75$, and a significant interaction between the variables, $F(1,14)=36.75$. Analysis of simple effects showed that the change from Trial 1 to Trial 2 was significant in the paired group, $F(1,14)=71.48$, but not in the unpaired group $(F<1)$.

In the test phase 7 of the 8 rats in the paired group drank more of BX than of CX. The remaining subject refused to drink in the test (an effect not seen in previous, or subsequent, experiments in which all animals drank substantial amounts of both test fluids). The results for this aberrant subject were excluded before the means presented in Figure 1 were computed. As the lower panel of the figure shows, the paired group drank more of BX than CX (replicating the results of Experiments 1a and 1b); the unpaired group, by contrast, drank almost identical amounts of the two solutions. An ANOVA, with flavor (BX or CX) and group (paired or unpaired) as the variables, showed there to be a significant effect of flavor, $F(1,13)=7.14$, no significant effect of group $(F<1)$, but a significant interaction between the variables $F(1$, $13)=6.73$. A simple-effects analysis showed that the scores for $\mathrm{BX}$ and $\mathrm{CX}$ differed significantly for the paired group, $F(1$, $13)=12.99$, but not for the unpaired group $(F<1)$. We conclude that the difference in performance to $\mathrm{BX}$ and $\mathrm{CX}$ in the paired group of this experiment (and in Experiments 1a and 1b) depends on the conditioning of an aversion to AX.

\section{Experiment 2}

The perceptual learning effect obtained in Experiment 1 is not to be explained in terms of latent inhibition. As we have acknowledged, it is possible that latent inhibition may play a role in the between-subjects version of the effect-that the effect would arise if latent inhibition of the common stimulus elements (such as the $\mathrm{X}$ element) were to develop more readily in the intermixed group than in the blocked group. Such a mechanism could not be responsible, however, for the effect obtained in the within-subjects design in which each animal experiences the $\mathrm{X}$ element (and other elements common to the three stimuli) in both the intermixed arrangement (i.e., on the $\mathrm{AX}-\mathrm{BX}$ days) and the blocked arrangement (on the CX trials). Whatever the contribution made by the aversion acquired by $\mathrm{X}$ on the reinforced $\mathrm{AX}$ trials to the performance shown on test, it must be assumed to be the same on both BX and $\mathrm{CX}$ tests. The difference in the aversion controlled by the two test stimuli must have some other source.

The logic of the argument just advanced seems to imply that the associative strength acquired by common stimulus elements is irrelevant to the results obtained in Experiment 1. Although it is impossible to eliminate them entirely (the flavor stimuli used in these experiments necessarily share some intrinsic common elements), it should be possible to reduce the salience of common elements dramatically by omitting the explicitly added $\mathrm{X}$ element, the quinine that was added to $\mathrm{A}, \mathrm{B}$, and $\mathrm{C}$ in the preceding experiments. In the present experiment, therefore (see Table 1), one group of rats (the $\mathrm{X}$ group) was trained with the stimuli and procedures used in Experiment 1, with expectation that these subjects would consume more of BX than of CX on test. A second group (the no-X group) was treated identically, except that the $\mathrm{X}$ element was omitted throughout; that is, these rats were preexposed to $\mathrm{A}$ and $\mathrm{B}$ (intermixed) and to $\mathrm{C}$, conditioned with $\mathrm{A}$, and tested with $\mathrm{B}$ and $\mathrm{C}$. The question of interest was whether this 
treatment would generate the parallel result, with consumption of $\mathrm{B}$ being greater than of $\mathrm{C}$ in the test phase.

\section{Method}

The subjects were 16 naive male hooded Lister rats, with a mean ad lib weight of $340 \mathrm{~g}$ at the start of the experiment. Eight rats (the $\mathrm{X}$ group) received preexposure to $\mathrm{AX}, \mathrm{BX}$, and $\mathrm{CX}$, the procedures being the same as those described for Experiments 1a. The remaining rats (the no-X group) received identical treatment, except that the $X$ element (quinine) was omitted. The flavors used for these animals were thus $2 \%$ lemon (A), and $.160 \mathrm{M}$ saline and $.165 \mathrm{M}$ sucrose (B and $\mathrm{C}$, counterbalanced). After preexposure, the $\mathrm{X}$ group received two reinforced trials, with $\mathrm{AX}$ as the $\mathrm{CS}$, followed by test trials with $\mathrm{BX}$ and $\mathrm{CX}$. The no-X group received two conditioning trials, with $\mathrm{A}$ as the $\mathrm{CS}$, and test trials with $\mathrm{B}$ and $\mathrm{C}$. In details not specified here the procedure was the same as that described for the previous experiments.

\section{Results and Discussion}

The conditioning procedure was effective in establishing an aversion to the $\mathrm{CS}$ in both groups. The $\mathrm{X}$ group drank $9.62 \mathrm{ml}$ on the first conditioning trial (with $\mathrm{AX}$ ) and $3.52 \mathrm{ml}$ on the second; the no-X group drank $9.45 \mathrm{ml}$ on the first trial (with A) and 6.60 $\mathrm{ml}$ on the second. An ANOVA showed there to be significant effects of group, $F(1,14) 9.55$, and trial, $F(1,14)=76.34$, and significant effects of the interaction between these variables, $F(1$, $14)=8.68$. Analysis of simple effects showed that the change from Trial 1 to Trial 2 was significant in both groups. For the $\mathrm{X}$ group, $F(1,14)=68.26$; for the no-X group, $F(1,14)=16.76$. The aversion appeared to be stronger in the $X$ group than in the no-X group and their Trial 2 scores differed significantly, $F(1$, $28)=18.24$. This difference presumably reflects the fact that the $\mathrm{X}$ element (quinine) conditioned readily, either because it is particularly salient, or intrinsically somewhat aversive, or both.

The results of the test phase (group means) are presented in Figure 2. Not surprisingly, given the results of the conditioning phase, overall levels of consumption were higher in the no-X

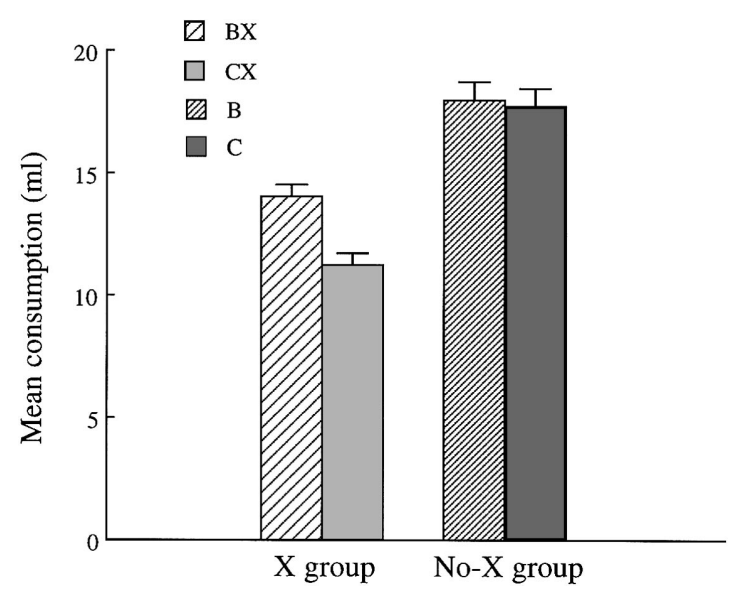

Figure 2. Experiment 2: Group mean consumption of the compound flavors BX and CX or the simple flavors B and C after conditioning with $\mathrm{AX}$ (the $\mathrm{X}$ group) or $\mathrm{A}$ (the no- $\mathrm{X}$ group). The $\mathrm{X}$ group received initial preexposure to a block of $\mathrm{CX}$ trials and to trials with $\mathrm{AX}$ and $\mathrm{BX}$ presented in alternation; the no- $\mathrm{X}$ group received equivalent treatment but with the $\mathrm{X}$ element omitted. Error bars represent within-subjects standard errors. group than in the $\mathrm{X}$ group. For the $\mathrm{X}$ group, consumption of $\mathrm{BX}$ was greater than consumption of $\mathrm{CX}$, replicating the results for the corresponding groups of Experiments 1 and 2. The no-X group, on the other hand, consumed similar amounts of the two test flavors, B and C. Statistical analysis largely confirmed this description. An ANOVA, with group and flavor as the variables, showed there to be a significant effect of group, $F(1,14)=43.02$, but no significant main effect of flavor, $F(1,14)=3.02$. But although the difference in the means for the $\mathrm{X}$ group was clearly much larger than that for the no- $\mathrm{X}$ group, the interaction between the variables of group and flavor did not achieve significance, $F(1,14)=1.91$. In order to confirm, therefore, that the effect observed in Experiment 1 could be obtained in the $\mathrm{X}$ group of this experiment, we conducted a separate analysis on the means for this group, equivalent to that used in Experiment 1. This analysis revealed a significant difference between the $\mathrm{BX}$ and $\mathrm{CX}$ scores, $F(1,7)=8.35$. An equivalent analysis for the no-X group produced no significant difference in the amounts of $\mathrm{B}$ and $\mathrm{C}$ consumed $(F<1)$. On the basis of these analyses we feel justified in concluding that the within-subjects version of the perceptual learning effect cannot be obtained in the absence of a salient stimulus element common to all the cues (for a similar finding in the between-subjects procedure, see Mackintosh, Kaye, \& Bennett, 1991).

It is possible that the failure to find a difference in the no- $X$ group reflects the operation of a "ceiling effect"; that is, any difference in the response to B and C may be difficult to detect at the high levels of consumption shown by this group. These levels were not, however, a consequence of any inadequacy in the conditioning procedure, which was clearly effective in establishing an aversion to A. Instead, we may conclude that there was rather little generalization between $\mathrm{A}$ and $\mathrm{B}$ and between $\mathrm{A}$ and $\mathrm{C}$ - that these stimuli share few intrinsic common elements or that these elements acquired little strength during conditioning to A and thus could not mediate generalization of the aversion. In either case the result serves to demonstrate that the perceptual learning effect will only be seen when the stimuli being tested have a salient common element. To understand why this is so should shed light on the nature of the effect itself and analysis of the role of the common element forms the focus of the remaining experiments.

\section{Experiment 3}

With the within-subjects design used in these experiments, the associative strength governed by the $\mathrm{X}$ element cannot be directly responsible for the differing levels of consumption of BX and CX seen in Experiment 1 and in the $\mathrm{X}$ group of Experiment 2. Nonetheless, the $\mathrm{X}$ element clearly plays a key role, as the results for the no-X group of Experiment 2 show. In order to guide our thinking about what this role might be, we attempted in this experiment to determine if the $\mathrm{X}$ element exerted its effects at just one stage in the training procedure. Our results so far have shown that the perceptual learning effect is obtained when $\mathrm{X}$ is present throughout training. For the $\mathrm{X}-\mathrm{P}$ group ( $\mathrm{P}$ for preexposure) of the present experiment, we included the $\mathrm{X}$ element during the preexposure phase (i.e., we gave preexposure to $\mathrm{AX}, \mathrm{BX}$, and $\mathrm{CX}$, as in Experiment 1), but we gave conditioning to the A element alone followed by a test with $\mathrm{B}$ and $\mathrm{C}$, as for the no-X group of Experiment 2. The question of interest was whether having $\mathrm{X}$ present during preexposure would be enough to generate a differ- 
ence in the generalized responding shown to B and C. A second group allowed investigation of the parallel case in which the $\mathrm{X}$ element was omitted during preexposure. The $\mathrm{X}-\mathrm{CT}$ group $(\mathrm{C}$ for conditioning, $\mathrm{T}$ for test) received preexposure to the $\mathrm{A}, \mathrm{B}$, and $\mathrm{C}$ elements (as for the no-X group of Experiment 2), followed by conditioning with the $\mathrm{AX}$ compound and a test with $\mathrm{BX}$ and $\mathrm{CX}$.

\section{Method}

The subjects were 16 naive male hooded Lister rats, with a mean ad lib weight of $485 \mathrm{~g}$ at the start of the experiment. Eight rats (the X-P group) received preexposure to $\mathrm{AX}, \mathrm{BX}$, and $\mathrm{CX}$, the procedures being the same as those described for Experiments 1a and 1c. The remaining rats (the no-CT group) received identical treatment, except that the $\mathrm{X}$ element (quinine) was omitted, as in Experiment 2. After preexposure, the X-P group received two reinforced trials with $\mathrm{A}$ as the $\mathrm{CS}$ followed by test trials with $\mathrm{B}$ and $\mathrm{C}$. The $\mathrm{X}-\mathrm{CT}$ group received two conditioning trials with $\mathrm{AX}$ as the CS, and test trials with $\mathrm{BX}$ and $\mathrm{CX}$. In details not specified here the procedure was the same as that described for the previous experiments.

\section{Results and Discussion}

Conditioning proceeded much more readily in the $\mathrm{X}-\mathrm{CT}$ group than in the X-P group. The X-CT group drank $9.02 \mathrm{ml}$ on the first conditioning trial and $5.03 \mathrm{ml}$ on the second; the equivalent scores for the X-P group were $8.69 \mathrm{ml}$ and $8.59 \mathrm{ml}$, with 6 rats showing a reduction in consumption across the trials, and 2 rats showing an increase. An ANOVA showed there to be a significant effect of group, $F(1,14)=6.32$, and trial, $F(1,14)=8.88$, and a significant interaction between these variables, $F(1,14)=8.02$. A simple effects analysis showed that the difference between the trials was significant in the X-CT group, $F(1,14)=16.88$, but not in the $\mathrm{X}-\mathrm{P}$ group $(F<1)$. This difference presumably reflects the fact that a novel, salient stimulus element $(\mathrm{X})$ was present during conditioning for the $\mathrm{X}-\mathrm{CT}$ group, which received $\mathrm{AX}$ as the $\mathrm{CS}$, whereas the X-P group was conditioned with A alone. It should not be concluded, however, that the conditioning procedure was without effect in the X-P group. In a separate study, conducted for other reasons, we gave rats preexposure to $\mathrm{AX}$ and conditioning with $\mathrm{A}$, as in the present experiment, but followed this with a test trial in which A was presented alone. The rats drank the full amount offered on the conditioning trials (as here), but consumption was almost totally suppressed on the test trial, indicating that an aversion had been acquired as a result of the conditioning trials.

The results of the test trials are presented in Figure 3. As might be expected, given the results of the conditioning phase, the X-P group consumed substantially more of the test flavors than did the $\mathrm{X}-\mathrm{CT}$ group. In neither group, however, was there any sign of a difference between the two flavors in the amount consumed. An ANOVA was conducted on the data summarized in the figure, the variables being group (X-P vs. X-CT) and flavor (B or BX vs. C or $\mathrm{CX})$. This yielded only a significant effect of group, $F(1$, 14) $=85.62($ other $F$ s $<1)$.

These results, taken together with those of Experiment 2, demonstrate that the perceptual learning effect will be found only when the critical stimuli (A, B, and C) are compounded with a common element both during preexposure and in the conditioning and test phases. This outcome is entirely consistent with the associative theory of perceptual learning proposed by McLaren et al. (1989; see also McLaren \& Mackintosh, 2000). As in the betweensubjects design, intermixed preexposure to the compounds $\mathrm{AX}$ and

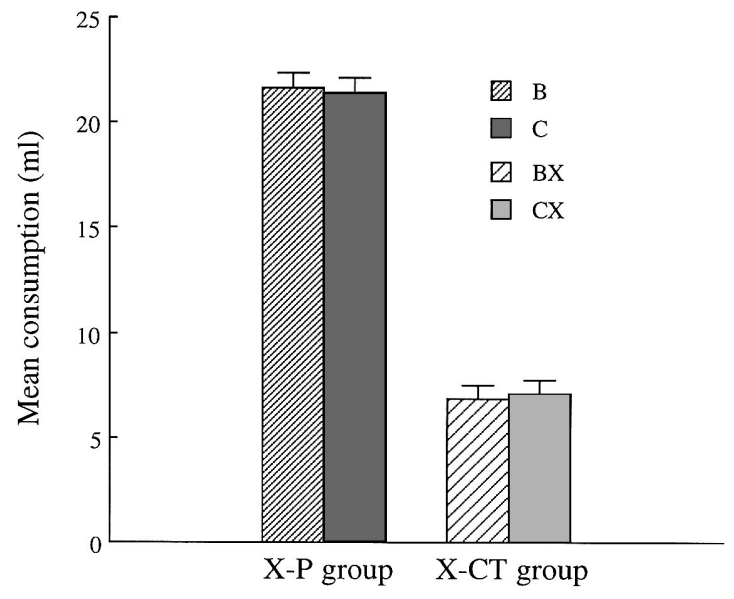

Figure 3. Experiment 3: Group mean consumption of the compound flavors BX and CX or the simple flavors B and $\mathrm{C}$ after conditioning with A (the $\mathrm{X}-\mathrm{P}$ group) or $\mathrm{AX}$ (the $\mathrm{X}-\mathrm{CT}$ group). The $\mathrm{X}-\mathrm{P}$ group received initial preexposure to a block of $\mathrm{CX}$ trials and to trials with $\mathrm{AX}$ and $\mathrm{BX}$ presented in alternation; the $\mathrm{X}-\mathrm{CT}$ group received equivalent treatment but with the $\mathrm{X}$ element omitted. Error bars represent within-subjects standard errors.

$\mathrm{BX}$ will allow the formation of excitatory links between $\mathrm{A}$ and $\mathrm{X}$ and between $\mathrm{B}$ and $\mathrm{X}$ and the formation of inhibitory links between the unique elements, A and B. Exposure to CX will allow formation of the $\mathrm{X}-\mathrm{C}$ excitatory association, but inhibitory links between $\mathrm{C}$ and $\mathrm{A}$ (or B) seem unlikely to form. (For C to form an inhibitory link with A, for example, it will be necessary, on CX trials, for $\mathrm{X}$ to activate the representation of the absent $\mathrm{A}$. This will be impossible for the subgroup that experiences the block of $\mathrm{CX}$ trials prior to exposure to $\mathrm{AX}$; and for the subgroup that experiences $\mathrm{CX}$ after exposure to $\mathrm{AX}$, the critical $\mathrm{X}$-A association might be expected to extinguish over the course of the CX trials.) Thus, after conditioning with $\mathrm{AX}$, the $\mathrm{X}-\mathrm{A}-\mathrm{US}$ chain will contribute to the conditioned response seen on $\mathrm{CX}$ test trial, whereas the inhibitory link between B and A will eliminate this source of responding on the BX test trial.

According to this account, the $\mathrm{X}$ element plays a dual role: First, its presence on the preexposure trials is necessary for the formation of within-compound excitatory associations and the inhibitory associations between $\mathrm{A}$ and $\mathrm{B}$; second, it must be present on the test trials to activate the representation of A (and thus of the US). What follows is that there is no reason to expect any difference in performance to the test stimuli if no $\mathrm{X}$ element is presented (the result obtained in Experiment 2), if $X$ is omitted during the test phase (Experiment 3a), or if $\mathrm{X}$ is omitted during the preexposure phase (Experiment 3b). In the next experiment we tested a further implication of this account.

\section{Experiments $4 \mathrm{a}$ and $4 \mathrm{~b}$}

Experiments 2 and 3 show that the perceptual learning effect depends on the presence of a common element throughout the procedure. They do not tell us, however, whether the effect depends on the same element being present in all stages of the procedure, and this matter was investigated in Experiment 4. In Experiment 4a (see Table 1) rats were given preexposure, as before, to intermixed presentations of the compounds $\mathrm{AX}$ and $\mathrm{BX}$, 
and to CX in a separate block of trials. For the conditioning and test phases, however, the nature of the explicitly added common element was changed; that is, conditioning was given with AY as the CS, and the test flavors were BY and CY. The question of interest was whether what we have referred to as the perceptual learning effect (greater consumption of the compound containing $\mathrm{B}$ than of the compound containing $\mathrm{C}$ ) would be obtained in these conditions. At face value, the associative account predicts that no effect will be found in this case. Preexposure must be supposed to be effective in establishing an inhibitory link between B and A, but this link will only be able to determine test performance if the test stimulus has a tendency to activate the A representation. Because $\mathrm{X}$ is not present on test, the excitatory $\mathrm{X}-\mathrm{A}$ link formed during preexposure will not be able to play this role. It is theoretically possible that direct generalization from $\mathrm{B}$ and from $\mathrm{C}$ might be capable of activating the A representation in this procedure but, as we have already seen (Experiment 2b), there is little evidence of generalization among these stimuli.

Although the particular flavors used as $\mathrm{X}$ and $\mathrm{Y}$ in Experiment $4 \mathrm{a}$ seemed to us to be easily discriminable, it is possible that rats may generalize between them. If so, then the experimental design just outlined reduces to that already used (e.g., in Experiment 1) in which the same common element was present throughout. To find that the rats consumed more of BY than CY on test (the result, to anticipate, that was obtained in Experiment $4 \mathrm{a}$ ) would thus not constitute an advance on the effects previously demonstrated. Accordingly, we conducted a further study (Experiment $4 \mathrm{~b}$; see Table 1) that paralleled Experiment $4 \mathrm{a}$ in that preexposure was given with $\mathrm{AX}, \mathrm{BX}$, and $\mathrm{CX}$, and the test was given with $\mathrm{BY}$ and $\mathrm{CY}$. The stimulus used in the conditioning phase, however, was AX. If the effect observed in Experiment $4 \mathrm{a}$ occurs because of generalization between X and Y, then it is to be expected that conditioning with AX rather than with AY would be without influence on the results and that the rats in Experiment $4 \mathrm{~b}$ would again drink more of BY than $\mathrm{CY}$ on the test.

\section{Method}

The subjects were 16 experimentally naive male hooded Lister rats, with a mean ad lib weight of $392 \mathrm{~g}$ at the start of the experiment. Eight were used in Experiment 4a, and 8 were used in Experiment $4 \mathrm{~b}$. As in previous experiments, Flavor A was lemon and Flavors B and C were sucrose and saline, respectively. The flavors used as $\mathrm{X}$ and $\mathrm{Y}$ were quinine (as before) and a $1 \%$ solution of vanilla (vanilla essence from Supercook, Leeds, United Kingdom).

In Experiment 4a the rats received preexposure to $\mathrm{AX}, \mathrm{BX}$, and $\mathrm{CX}$, followed by two reinforced trials with AY, and test trials with BY and CY. For half of the rats $\mathrm{X}$ was quinine and $\mathrm{Y}$ was vanilla; for the rest the arrangement was reversed. In all other respects the procedure was the same as that described for Experiment 1a. Experiment $4 \mathrm{~b}$ was identical to Experiment $4 \mathrm{a}$, except that conditioning was given with $\mathrm{AX}$ as the CS.

\section{Results and Discussion}

The conditioning phase established an aversion to AY in Experiment $4 \mathrm{a}$. Group mean consumption was $8.75 \mathrm{ml}$ on Trial 1 and $4.13 \mathrm{ml}$ on Trial 2, with all subjects showing a reduction from the first trial to the second. In Experiment 4b, the rats drank a mean of $8.66 \mathrm{ml}$ on Trial 1 of conditioning with $\mathrm{AX}$ and drank a mean of $5.42 \mathrm{ml}$ on Trial 2, with 7 of the 8 rats showing a reduction.

Group means for the test trials of Experiment $4 \mathrm{a}$ are shown in the left-hand portion of Figure 4. As in the earlier experiments in

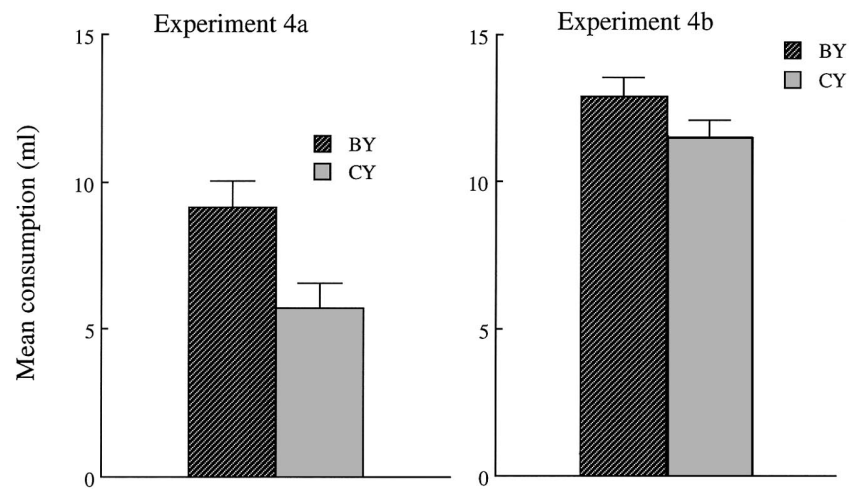

Figure 4. Experiment 4: Group mean consumption of the compound flavors BY and CY after conditioning with AY (Experiment 4a) or AX (Experiment 4b). All animals received initial preexposure to a block of CX trials and to trials with $\mathrm{AX}$ and $\mathrm{BX}$ presented in alternation. Error bars represent within-subjects standard errors.

which the same common element was present throughout, the rats drank more of the compound containing $\mathrm{B}$ than of the compound containing $\mathrm{C}$ (in this case more of BY than $\mathrm{CY}$ ). In other unpublished work, we have found that animals given a solution containing quinine will drink less than those given a solution containing vanilla, and this factor was included as a variable in an ANOVA along with the within-subjects variable of test stimulus (BY or $\mathrm{CY})$. The effect of vanilla versus quinine proved to be nonsignificant $(F<1)$, as did the interaction of the variables, $F(1$, $6)=3.45$, but there was a significant effect of BY versus $C Y, F(1$, 6) $=5.80, p=.05$.

If the result obtained in Experiment $4 \mathrm{a}$ occurred because the rats failed to discriminate between the flavors used as $\mathrm{X}$ and $\mathrm{Y}$, then the same effect should be observed in Experiment $4 \mathrm{~b}$ in which the $\mathrm{X}$ element was presented during conditioning. The group means for the test trials of Experiment $4 \mathrm{~b}$ are shown in the right-hand portion of Figure 4. Levels of consumption were higher (in this experiment, the test stimuli did not include any element that had undergone direct conditioning in the previous phase), but there was no substantial difference between BY and CY. An ANOVA paralleling that conducted for Experiment $4 \mathrm{a}$ yielded a significant difference only between the subgroup given vanilla as $\mathrm{Y}$ (mean consumption: $15.30 \mathrm{ml}$ ) and that given quinine as $\mathrm{Y}$ (mean consumption: $9.09 \mathrm{ml}), F(1,6)=19.77$. (That this difference between quinine and vanilla failed to appear in Experiment 4a presumably means that the rats' normal pattern of preference was obscured in that experiment as a result of the conditioning trials given with AY. In this experiment the $\mathrm{Y}$ element was novel on the test trials.) Neither the difference between BY and CY, $F(1,6)=1.40$, nor the interaction between the variables $(F<1)$ was significant.

The effect obtained in Experiment 4a was not anticipated on the basis of the version of the associative theory of McLaren et al. (1989) discussed previously. It is possible, however, that this theory can be extended to deal with it. Recall that for inhibition between B and A to influence test performance it is necessary for the test stimuli to activate the representation of the (conditioned) element A. Because X was not present on the test, the excitatory $\mathrm{X}-\mathrm{A}$ association formed during preexposure would be ineffective in this regard. It is possible, however, that the two AY trials of the conditioning phase resulted in the formation of a within-compound 
Y-A association. If so, then the representation of A could be activated by the $\mathrm{Y}$ element in rats tested with $\mathrm{BY}$ and $\mathrm{CY}$, and B-A inhibition could still act to reduce the degree of the aversion shown to the BY compound. Whether two AY trials would be sufficient to establish an appropriately strong Y-A association is open to debate, particularly in view if the fact that each was followed by a potent US, a procedure known to detract from the formation of within-compound associations (Holland, 1980). This doubt was enough to encourage us to attempt another, and potentially more decisive, test of the alternative theories.

\section{Experiments $5 \mathrm{a}$ and $5 \mathrm{~b}$}

According to Mondragón and Hall (2002), preexposure to alternating presentations of $\mathrm{AX}$ and $\mathrm{BX}$ enhances the perceptual effectiveness of the unique elements A and B (or at least, maintains this effectiveness at a higher level than that governed by the $\mathrm{C}$ element of $\mathrm{CX}$ ). This interpretation suggests the following explanation for the results reported so far. When animals are tested with BX after conditioning with $\mathrm{AX}$, the perceptually salient $\mathrm{B}$ element of the compound will dominate, $\mathrm{X}$ will be less readily perceived, and the aversion conditioned to this stimulus will be unable to show itself fully; $\mathrm{C}$, on the other hand, will be less likely to interfere with the perception of $\mathrm{X}$, and a stronger aversion should be evident. A parallel result can be expected when (as in Experiment 4a) conditioning is given with $\mathrm{AY}$, and $\mathrm{BY}$ and $\mathrm{CY}$ are tested, the only difference being that, in this case, $\mathrm{B}$ and $\mathrm{C}$ will exert their differing effects on the aversion governed by $\mathrm{Y}$. No difference is predicted when, as in Experiment 4b, B and C are compounded on test with a stimulus element that has not undergone conditioning.

An implication of this analysis is that it should not be necessary to use a compound such as $\mathrm{AX}$ as the CS to obtain the perceptual learning effect. This was tested in the present experiment. In Experiment 5a (see Table 1), rats received preexposure to alternating presentations of $\mathrm{AX}$ and $\mathrm{BX}$, and to $\mathrm{CX}$ on a separate block of trials. They were then conditioned with $\mathrm{X}$ as the CS prior to a test with $\mathrm{BX}$ and $\mathrm{CX}$. The degree of aversion shown on the test trials will depend on the rat's ability to perceive and respond to the conditioned $\mathrm{X}$ element. The hypothesis being tested suggests that $\mathrm{B}$, being perceptually more dominant that $\mathrm{C}$, will be more likely to interfere with perception of $\mathrm{X}$ and thus that a lesser aversion will be displayed to BX than to CX. The associative theory of McLaren et al. (1989) makes no such prediction. The mechanism proposed by this theory requires that the A element should undergo conditioning - the ability of B to inhibit the representation of A will be able to influence behavior only when A has some associative strength. Conditioning with $\mathrm{X}$ alone (rather than $\mathrm{AX}$ ) precludes the operation of this mechanism, and the theory thus predicts no difference between BX and CX on test.

According to the perceptual learning hypothesis of Mondragón and Hall (2002), the role of the X element in Experiment 5a is to evoke an aversion that is interfered with, to a greater or lesser extent, by the presence of $\mathrm{B}$ and $\mathrm{C}$ in the test phase. There is no necessity, given this interpretation, that the stimulus that plays this role should be the stimulus that was present as a common element during the preexposure phase. We investigated this matter in Experiment 5b. The design was identical to that of Experiment $5 \mathrm{a}$ (see Table 1), except that a novel stimulus, Y, was used in the conditioning phase, and the test stimuli were BY and CY. Again we predict that the perceptually dominant B should be better able to disrupt the aversive response to $\mathrm{Y}$ than the less dominant $\mathrm{C}$. And again, the associative account predicts that there will be no difference in responding to the two test compounds.

\section{Method}

The subjects for Experiment 5a were 8 naive male hooded Lister rats, with a mean ad lib weight of $362 \mathrm{~g}$ at the start of the experiment. An additional 8 rats from the same stock (mean ad lib weight: $333 \mathrm{~g}$ ) were used in Experiment 5b.

In Experiment 5a the rats received preexposure to $\mathrm{AX}, \mathrm{BX}$, and $\mathrm{CX}$, the flavors and procedures being identical to those described for Experiment 1a. They then received two conditioning trials with the $\mathrm{X}$ element (quinine) as the CS. This procedure resulted in a more substantial aversion than conditioning with the AX compound (presumably because the presence of $\mathrm{A}$ acts to overshadow $\mathrm{X}$ ), and consumption was low on the first test trials with $\mathrm{BX}$ and $\mathrm{CX}$. Accordingly testing was continued, in extinction, over the course of 6 days, with each rat receiving three presentations of BX and three presentations of $\mathrm{CX}$. Half of the animals received the sequence $\mathrm{BX}, \mathrm{CX}, \mathrm{CX}, \mathrm{BX}, \mathrm{BX}, \mathrm{CX}$, and half received the sequence $\mathrm{CX}, \mathrm{BX}, \mathrm{BX}$, $\mathrm{CX}, \mathrm{CX}, \mathrm{BX}$.

Experiment 5b was identical to Experiment 5a, except that conditioning was given with $\mathrm{Y}$, and the test was given with BY and CY. The flavors used as $\mathrm{X}$ and $\mathrm{Y}$ were quinine and the vanilla solution used in Experiment 4 (as that experiment has shown, there is little evidence of generalization between these flavors). For half of the rats quinine served as $\mathrm{X}$ and vanilla served as Y; for the remainder the arrangement was reversed. In respects not specified here, the procedure used in these experiments was the same as that described for Experiment 1

\section{Results and Discussion}

In Experiment 5a, in which the stimulus used as the CS had undergone extensive preexposure, there was little evidence of acquisition of an aversion after one conditioning trial. The amount consumed on Trial 1 was $9.09 \mathrm{ml}$, declining to $8.76 \mathrm{ml}$ on Trial 2, with only 6 of the 8 subjects showing a reduction in consumption. The results of the test phase confirm, however, that a substantial aversion was acquired after the second conditioning trial. In Experiment $5 \mathrm{~b}$, in which a novel CS (Y) was used, the mean amounts consumed were $8.30 \mathrm{ml}$ on Conditioning Trial 1 and $6.06 \mathrm{ml}$ on Conditioning Trial 2, with all animals showing a reduction across the trials.

The top panel of Figure 5 shows group mean consumption over the test trials, with BX and CX for Experiment 5a. The level of consumption was low on the first trial with each stimulus, although consumption of $\mathrm{BX}$ was marginally greater than consumption of CX. This difference between the flavors was increased on Trial 2 but absent in Trial 3, presumably as a result of extinction of the aversion. An ANOVA conducted on the data summarized in the figure showed there to be a significant effect of trial, $F(2$, $14)=29.10$, no significant main effect of flavor $(F<1)$, but a significant interaction between trial and flavor, $F(2,14)=4.03$. Pairwise comparisons (using the Newman-Keuls test) confirmed that the difference between the flavors was significant only on Trial 2.

The test results for Experiment 5b (lower panel of Figure 5) showed a similar pattern to those of Experiment 5a. Again consumption was suppressed on the initial test trials and recovered with continued testing; and again, more was consumed of the compound containing B (in this case BY) than of that containing $\mathrm{C}(\mathrm{CY})$. In this experiment the difference between the flavors was 


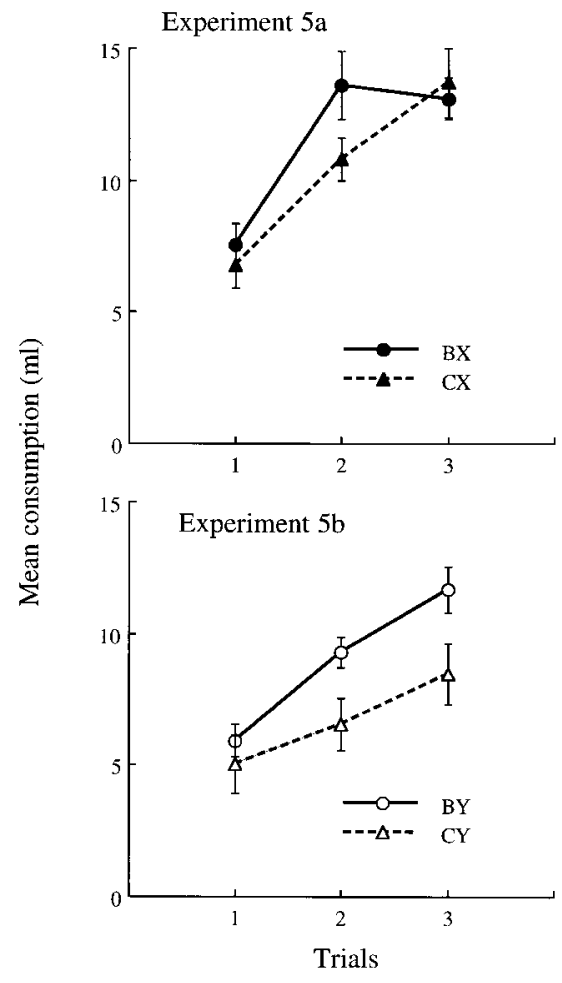

Figure 5. Experiment 5: Group mean consumption of the compound flavors BX and CX after aversion conditioning with X (Experiment 5a) and of the compound flavors BY and CY after conditioning with Y (Experiment $5 \mathrm{~b}$ ). All animals received initial preexposure to a block of CX trials and to trials with $\mathrm{AX}$ and $\mathrm{BX}$ presented in alternation. Error bars represent within-subjects standard errors.

evident throughout the test. An ANOVA yielded a significant effect of trial, $F(2,14)=13.31$, and a significant main effect of flavor, $F(1,7)=7.17$; the interaction was not significant $(F<1)$.

These experiments demonstrate that the aversion controlled by a conditioned flavor ( $\mathrm{X}$ in Experiment 5a, $\mathrm{Y}$ in Experiment 5b) will be modulated by the presence of another preexposed flavor. The aversion is less when the added flavor is one (B) that has been preexposed in alternation with some other similar flavor (i.e., has been experienced in a sequence of alternating $\mathrm{AX}-\mathrm{BX}$ trials) than when the added flavor $(\mathrm{C})$ has been preexposed on a separate block of $(\mathrm{CX})$ trials. This outcome is not predicted by the associative account of preexposure effects developed by McLaren et al. (1989). As we have said, the mechanism envisaged by this theory can operate only when the rats have experienced conditioning with the A element, which did not happen either in Experiment $5 \mathrm{a}$ or $5 \mathrm{~b}$. The results are entirely consistent, however, with the proposal that the perceptual effectiveness of the $\mathrm{B}$ element is greater than that of the $\mathrm{C}$ element and that the behavior shown toward the test compounds is a consequence of the degree to which the added elements are able to interfere with the response governed by the conditioned element.

\section{General Discussion}

Earlier work (e.g., Symonds \& Hall, 1995) has shown preexposure to two compound flavors (AX and BX) presented in alterna- tion will attenuate the extent to which an aversion conditioned to AX will generalize to BX. The present experiments (Experiments $1 \mathrm{a}, 1 \mathrm{~b}$, and $1 \mathrm{c}$ ) have confirmed the reliability of this effect using a within-subjects design. In this experiment, the rats were given alternating trials with $\mathrm{AX}$ and $\mathrm{BX}$ and exposure to a third compound, CX, on a separate block of trials. After conditioning with $\mathrm{AX}$ as the CS, it was demonstrated that the aversion controlled by CX was greater than that controlled by BX. This result was taken to be an instance of a perceptual learning effect, with the animals being better able to discriminate $\mathrm{BX}$ from $\mathrm{AX}$ than $\mathrm{CX}$ from AX.

In previous demonstrations of the perceptual learning effect, it is possible that changes in the properties of Stimulus X, the common element, may have played an important role. Mondragón and Hall (2002), using a between-subjects design, found that conditioning with $\mathrm{AX}$ endowed $\mathrm{X}$ with less associative strength in rats given intermixed preexposure than in control subjects. But with the present experimental design, in which the same animals experience the same $\mathrm{X}$ stimulus on the test trials, some other factor must be responsible-preexposure must be assumed to have differing effects on the unique features of the compounds (i.e., on A, B, and C). This is not to say that the common element plays no part. There was no difference between the $\mathrm{B}$ and $\mathrm{C}$ flavors on test when the $\mathrm{X}$ element was omitted throughout (Experiment 2), or was present just during preexposure (Experiment 3a), or was present just during the conditioning and test phases of the procedure (Experiment $3 b$ ). The role of the common element was investigated in Experiments 4 and 5. These showed that it was not necessary for the same common element to be used throughout the procedure for the perceptual learning effect to be obtained; animals conditioned with $\mathrm{AY}$ after preexposure to $\mathrm{AX}, \mathrm{BX}$, and $\mathrm{CX}$ showed a greater aversion to CY than to BY on test (Experiment 4a). Nor was it necessary for conditioning to be given with a compound containing one of the preexposed elements. Experiment 5a showed there to be a greater aversion to $\mathrm{CX}$ than to $\mathrm{BX}$ after conditioning with $\mathrm{X}$ alone; Experiment $5 \mathrm{~b}$ revealed a similar effect, a greater aversion to $\mathrm{CY}$ than to BY, after conditioning with a novel element (Y) as the CS.

These latter results (especially those of Experiment 5) constitute a problem for the associative theory of perceptual learning put forward by McLaren et al. (1989). Central to the mechanism proposed by this theory is that the test stimuli be able to activate the representation of the conditioned element $\mathrm{A}$ in the test phase. This is not possible with the design used in Experiment 5, in which the A element did not undergo conditioning. These results are to be expected, however, on the basis of the account of perceptual learning outlined by Mondragón and Hall (2002). According to this account, alternating exposure to two similar stimuli, such as $\mathrm{AX}$ and $\mathrm{BX}$, engages a learning process that enhances the perceptual effectiveness of the unique, distinctive features of the stimuli (and also, although this is not relevant to the explanation of the results obtained with the present experimental design, reduces the effectiveness of their common elements). When animals are tested with the compounds BX and CX, as in Experiments 1, 2, and 5a (or BY and CY in Experiments $4 a$ and 5b), the degree to which they show an aversion will be determined by the readiness with which they perceive the conditioned element X (or Y). The more salient $\mathrm{B}$ will interfere with perception of the conditioned element more effectively than will the less salient $\mathrm{C}$, and the aversion shown to 
the compound containing $\mathrm{B}$ will be less than that shown to the compound containing $\mathrm{C}$.

It remains to specify how the learning process envisaged by this account might operate. Although the initial impetus for using the intermixed schedule came from the suggestion that this schedule might foster a process of comparison between the stimuli, it should be acknowledged that the arrangement used in the present studies was unlikely to be ideal for this. According to our intuition, comparison is most likely to occur when two events are presented simultaneously, or at least, so close together in time that the representation of one held in short-term memory will still be present when the other is perceived. In the present experiments, however, the interval between successive presentations of AX and BX was never less than $6 \mathrm{hr}$, and in other experiments (e.g., Symonds \& Hall, 1995, Experiment 1) the perceptual learning effect has been obtained with an interval of $24 \mathrm{hr}$. What is more, Bennett and Mackintosh (1999) have shown that decreasing the interval between presentations of the relevant stimuli during preexposure does not enhance the size of the perceptual learning effect, as might be expected if the effect depended on the process of comparison as it is usually conceived.

Evidently the special effectiveness of the intermixed schedule in producing perceptual learning effects cannot be attributed to the fact that this schedule allows direct comparison between the stimuli-alternating presentations of the stimuli are effective, apparently regardless of the interval between stimulus presentations. Mondragón and Hall (2002) have argued, however, that even with long intertrial intervals, comparison of a sort could occur between the stimulus that is currently presented and the memory of what was presented on a previous trial. They noted that associative principles could supply a mechanism by which this might occur. If the AX trial allows the formation of an $\mathrm{X}-\mathrm{A}$ association, then the presence of $\mathrm{X}$ on the subsequent $\mathrm{BX}$ trials will mean that the representation of A will be activated on that trial. Similarly, X will be able to activate the representation of $\mathrm{B}$ on the next $\mathrm{AX}$ trial. (Equivalent effects will not be possible on $\mathrm{CX}$ trials when these precede presentations of $\mathrm{AX}$ and $\mathrm{BX}$; and when the block of $\mathrm{CX}$ trials follows the $\mathrm{AX}-\mathrm{BX}$ trials, extinction should reduce the role of previously formed within-compound associations involving $\mathrm{X}$, A, and B.) Thus, according to the interpretation offered by Mondragón and Hall (2002), the intermixed schedule allows comparison to occur between the directly perceived A element and the associatively activated representation of $\mathrm{B}$, and between the directly perceived $\mathrm{B}$ element and the associatively activated representation of $\mathrm{A}$.

The mechanism (presumably nonassociative) by which this state of affairs produces changes in the effective salience of the stimulus elements still needs to be specified (Hall, 2003, offers some speculations), but the suggestion that this process depends on the operation of associative learning mechanisms supplies an expla- nation for a further aspect of the present results. Our experiments have shown that the perceptual learning effect can be obtained when the common element present on the test is quite different from that used during preexposure (e.g., Experiment 5b). It is still necessary, however, for there to be an element in common among $\mathrm{A}, \mathrm{B}$, and $\mathrm{C}$ during preexposure (Experiments 2 and $3 \mathrm{a}$ ). This is what would be expected on the basis of the interpretation just offered - the comparison process depends on the ability of one stimulus to activate the representation of the unique features of the other, and this will only be possible when the two stimuli share a common element that allows the necessary within-compound associations to be formed.

\section{References}

Bakeman, R., \& McArthur, D. (1996). Picturing repeated measures: Comments on Loftus, Morrison, and others. Behavior Research Methods, Instruments, \& Computers, 28, 584-589.

Bennett, C. H., \& Mackintosh, N. J. (1999). Comparison and contrast as a mechanism of perceptual learning? Quarterly Journal of Experimental Psychology, 52B, 253-272.

Dwyer, D. M., Bennett, C. H., \& Mackintosh, N. J. (2001). Evidence for inhibitory associations between the unique elements of two compound flavours. Quarterly Journal of Experimental Psychology, 54B, 97-107.

Hall, G. (1991). Perceptual and associative learning. Oxford, England: Clarendon Press.

Hall, G. (2003). Learned changes in the sensitivity of stimulus representations: Associative and nonassociative mechanisms. Quarterly Journal of Experimental Psychology, 56B, 45-57.

Holland, P. C. (1980). Second-order conditioning with and without unconditioned stimulus presentation. Journal of Experimental Psychology: Animal Behavior Processes, 6, 238-250.

Mackintosh, N. J., Kaye, H., \& Bennett, C. H. (1991). Perceptual learning in flavour aversion conditioning. Quarterly Journal of Experimental Psychology, 53B, 297-322.

McLaren, I. M. L., Kaye, H., \& Mackintosh, N. J. (1989). An associative theory of the representation of stimuli: Applications to perceptual learning and latent inhibition. In R. G. M. Morris (Ed.), Parallel distributed processing: Implications for psychology and neurobiology (pp. 102130). Oxford, England: Clarendon Press.

McLaren, I. M. L., \& Mackintosh, N. J. (2000). An elemental model of associative learning: I. Latent inhibition and perceptual learning. Animal Learning \& Behavior, 28, 211-246.

Mondragón, E., \& Hall, G. (2002). Analysis of the perceptual learning effect in flavour aversion learning: Evidence for stimulus differentiation. Quarterly Journal of Experimental Psychology, 55B, 153-169.

Symonds, M., \& Hall, G. (1995). Perceptual learning in flavor aversion learning: Roles of stimulus comparison and latent inhibition of common elements. Learning and Motivation, 26, 203-219.

Received April 23, 2002

Revision received September 3, 2002

Accepted September 5, 2002 